\title{
ASSESSMENT OF AWARENESS AND PRACTICE OF IONIZING RADIATION PROTECTION PROCEDURES AMONG EXPOSED HEALTH CARE WORKERS
}

\author{
By
}

Salah Eldeen $\mathrm{NG}^{1}$ and Farouk $\mathrm{SA}^{2}$

${ }^{1}$ Department of Community, Environmental and Occupational Medicine,${ }^{2}$ Department of Nuclear Medicine, Faculty of Medicine, Zagazig University, Egypt.

Corresponding author: Salah Eldeen NG: naneesghareeb@zu.edu.eg

\begin{abstract}
Introduction: Occupational exposure to ionizing radiation is the result of exposure at work sites for diagnostic and therapeutic practices. Ionizing radiation is an energy type in the form of electromagnetic waves or particles. Radiographic imaging is extremely valuable as a diagnostic tool in medical fields leading to different health hazards to health care workers (HCWs) and to the surrounding environment if safety measures are not observed. Aim of work: To assess awareness and practice of ionizing radiation protection procedures among (HCWs) occupationally exposed to ionizing radiation at Zagazig University Hospitals. Materials and methods: All HCWs (technicians, nurses, physicians, and physicists) occupationally exposed to ionizing radiation in diagnostic radiology (DR) department, Clinical Oncology and Nuclear Medicine (CO\&NM) department, and Nuclear Medicine (NM) unit who accepted to share in the study were included as study population $(\mathrm{No}=195)$. A cross-sectional study was carried out at the previous departments in Zagazig University Hospitals. A self-administered, structured questionnaire composed of three sections, A, B and C was the study tool. Section A comprised questions regarding demographic data, section $B$ included questions about awareness of radiation protection procedures, and section $\mathrm{C}$ was composed of questions about safe practices of HCWs regarding ionizing radiation exposures.
\end{abstract} Results: The study revealed that satisfactory awareness of radiation protection procedures among HCWs in the three departments was $(51.3 \%)$ with no statistically significant difference between different radiation units. But HCWs had inadequate practice score (18\%) regarding the use of safety measures of radiation exposure. Satisfactory awareness of radiation protection procedures of 
exposed workers was highly significantly associated with higher educational level (44.2\%), years of experience $\geq 10$ years $(36.8 \%)$, being a physician $(73.7 \%)$ and getting training courses $(61.1 \%)$. Also, adequate practice of radiation protection procedures among exposed workers was found to be highly significantly associated with higher educational level $(74.3 \%)$, years of experience $\geq 10$ years $(68.6 \%)$, being a physician $(80.0 \%)$ and getting training courses $(71.4 \%)$. Conclusion: satisfactory awareness about radiation protection procedures among exposed HCWs was noted while inadequate practices of radiation protection procedures in the workplace were found.

Keywords: Ionizing Radiation, Radiation Hazards, Radiation Protection Procedures, Awareness and Personal Protective Equipments.

\section{Introduction}

Ionizing radiations are emitted from radioactive atoms and the process is known as radioactivity. Ionizing radiations are composed of two types of energy: Electromagnetic radiation (gamma or X-rays) and particulate radiation (neutrons, beta or alpha particles).

In medical practice $20 \%$ of the total population is exposed to radiation and this is going to continue to increase all over the world. Annually worldwide, more than 3600 million diagnostic radiology examinations are conducted, 37 million nuclear medicine procedures are performed, and 7.5 million radiotherapy treatments are taken (WHO, 2016).

In the Nuclear Medicine departments (NMDs), nurses are responsible for patient preparation, organizing the use of radioactive and non-radioactive medications, demonstrating treatment procedures, and ensuring patient safety, which makes them more vulnerable to risks (Alotaibi et al., 2015).

Radiation has different health risks, which are affected by the dose level and exposure time; these include cancer, cataract, infertility and blood dyscrasias, genetically determined illhealth, developmental abnormalities, and degenerative diseases (Alotaibi et al., 2015 and Alzubaidi et al., 2017).

Staff working in radiation wards should have adequate knowledge about the risks and safety measures of radiation exposure to protect their health and help the patient to get the correct data about radiation exposure (Morishima et al., 2012). 
The risks of radiation are reduced by using different methods of protection like the principles of distance, and time as well as the use of various monitoring devices such as thermo-luminescent dosimeters (TLDs) and Geiger Muller (GM) counters (Bushong, 2012).

Shielding personal protective equipment include lead aprons, eye goggles, lead gloves, gonad shields, and thyroid shields. Regular use of lead aprons provides an average of 75-80\% protection to the bone marrow. Lead shielding is an important protective measure against radiation exposure (ElFeky et al., 2017)

In Egypt, radiation protection is specified in the Egyptian Law, Decree No. 59 (1960), on protection against ionizing radiation, which regulates licensing and the use of radiation sources. Open sources are the responsibility of the Atomic Energy Organization (AEO), but closed sources and X-ray machines and qualifications and training of personnel using them are the responsibility of the Ministry of Health and Population (MOHP). Both bodies (AEO and MOHP) inspect places using radiation sources and keep radiation and medical records of all exposed workers, as recommended by the International Atomic Energy Agency (IAEA , 2011)

Other Egyptian studies reported inadequate use of safety measures and practices in most ionizing radiation facilities (Abdellah et al., 2015 and ElFeky et al., 2017)

This research was carried out because it was noted that the level of awareness of the dangerous exposure to high levels of radiation by some health care workers in radiology departments was not adequate. Some neglected the use of personal dosimeters and others did not receive them. Deficiency of some mandatory radiation protection requirements like goggles and thyroid shields was noted. Other requirements like leaded gloves were very old and no longer useful.

\section{Aim of work}

To assess the level of awareness and practices of radiation protection procedures among workers occupationally exposed to ionizing radiation in Zagazig University Hospitals. 


\section{Materials and methods}

-Study design: This is a cross-sectional study.

-Place and duration of the study: The study was carried out in the Nuclear Medicine (NM) unit of Diagnostic Radiology (DR) department: Diagnostic Radiology (DR) department, Clinical Oncology and Nuclear medicine $(C O \& N)$ department in Zagazig University Hospitals during the period between August to October 2018.

-Diagnostic Radiology (DR) department includes:

- 2 units of Radiography, one unit of Mammography, 2 units of Computed Tomography and one unit of Interventional Radiology.

-Nuclear Medicine unit which is under supervision of DR department includes one Gamma Camera.

-Clinical Oncology and Nuclear Medicine department includes: one unit of Linear accelerator, one Cobalt unit and Dismantled Gamma Camera.

\section{-Study sample:}

All HCWs (physicians, nurses, technicians and physicists) occupationally exposed to ionizing radiation in the above mentioned departments, who agreed to participate in the study were included. The target population consisted of 105 out of 140 physicians, 57 out of 70 nurses, 33 out of 48 of technicians and physicists, a total of $(195 / 258)$, with a response rate of $(75.5 \%)$. Inclusion criteria: All health care workers (physicians, nurses, technicians and physicists) occupationally exposed to ionizing radiation in the three radiological departments with work experience at least one year and who accepted to participate in the study were included. Exclusion criteria: Any health care worker who attended less than one year in radiology departments. Any health care workers who were not in contact with radiation sources or with patients when they were being examined, for ex: (senior staff, pregnant female workers and outpatient clinic working nurses).

\section{-Study methods:}

The study tool in this research included A self-administered, structured questionnaire comprising of three sections: A, B and C. Section A comprised questions regarding demographic data, section B comprised 23 questions about awareness of 
radiation protection measures, and section $\mathrm{C}$ was composed of 7 questions about safe practices of $\mathrm{HCW}$ s regarding ionizing radiation exposures. The questionnaire was designed and validated after reviewing previous studies (Alotaibi et al., 2015 and ElFeky et al., 2017), and it was translated into Arabic and revised by 3 specialists. A pilot study was then conducted on 10 workers.

Scoring: The questions were answered by 'Yes' or 'NO'. Each positive answer was scored as 1 point and each negative answer was scored as 0 point. The awareness score ranged from 0 to 23 . Regarding practice, the score ranged from 0 to 7 . HCW who achieved more than two-thirds of the score of awareness or practice ( $>66.7 \%$ ) were considered to have satisfactory awareness or adequate practice of radiation protection procedures.

\section{Consent}

Before the start of work, an informed verbal consent was taken from subjects who agreed to participate in the study with assurance of confidentiality and .anonymity of data

\section{Ethical approval}

Approval from the Ethical Committee of Faculty of Medicine, Zagazig University Hospitals was obtained.

\section{Data management}

Data were presented and statistically analyzed using statistical package for social sciences (SPSS) version 19 (SPSS Inc. 2010). Descriptive variables were expressed as numbers and percentages, and mean \pm S.D. Chisquare was used to test for association between categorical variables. Pearson's correlation analysis was done to test the correlation between awareness and practices of health care workers. The level of significance was considered at $\mathrm{p}$ - value less than 0.05 . 


\section{Results}

Table (1): Demographic characteristics of HCWs who participated in the study (No= 195).

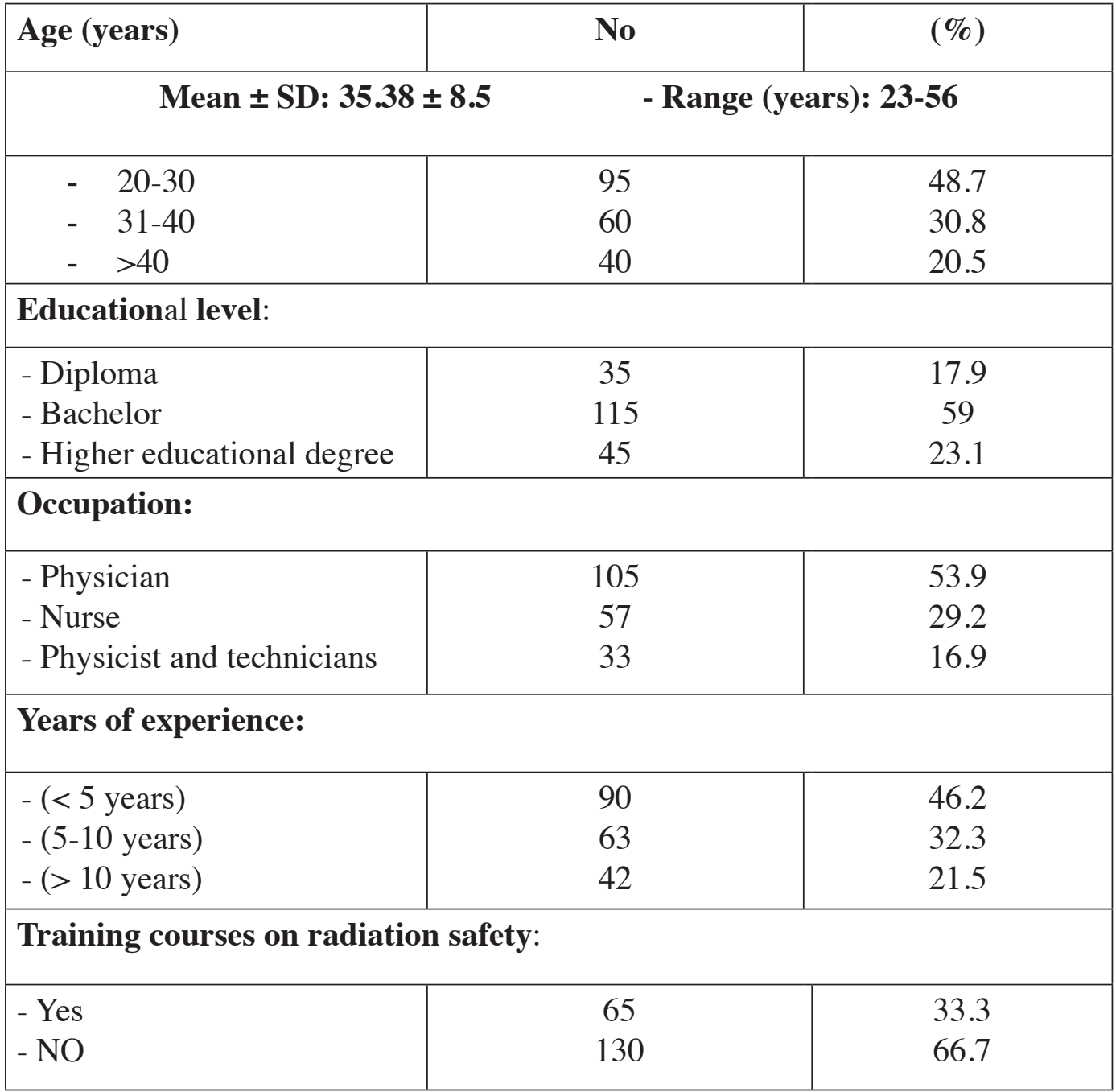

Table 1 showed a summary of demographic data of exposed health care workers. Over forty five percent (48.7\%) were aged between 20 and 30 years. The majority of workers $(59 \%)$ had bachelor degree. About (46\%) had less than five years of experience, and most of them $(66.7 \%)$ did not have training courses on radiation safety. 


\section{Table (2): Awareness of health care workers about radiation protection procedures $($ No $=195)$}

\begin{tabular}{|c|c|c|c|c|}
\hline \multirow[t]{2}{*}{ Radiation protection awareness } & \multicolumn{2}{|c|}{ Yes (1) } & \multicolumn{2}{|c|}{ NO (0) } \\
\hline & No & $\%$ & No & $\%$ \\
\hline Are you familiar with radioactive materials half-life $(\mathrm{T} 1 / 2) ?$ & 121 & 62.1 & 74 & 37.9 \\
\hline Do you know the term ALARA? & 92 & 47.2 & 103 & 52.8 \\
\hline Do you know what TLD badge or pocket dosimeter is? & 164 & 84.1 & 31 & 15.9 \\
\hline Are you familiar with Geiger-Muller survey meter? & 96 & 49.2 & 99 & 50.8 \\
\hline Do you know how to decontaminate radioactive spills? & 113 & 57.9 & 82 & 42.1 \\
\hline Are you familiar with the term radiation safety officer (RSO)? & 175 & 89.7 & 20 & 10.3 \\
\hline Are you familiar with the 10 days rule concept? & 65 & 33.3 & 130 & 66.7 \\
\hline Are you familiar with the following terms? & & & & \\
\hline Time, & 142 & 72.8 & 53 & 27.2 \\
\hline Distance & 160 & 82.1 & 35 & 17.9 \\
\hline Shielding & 163 & 83.6 & 32 & 16.4 \\
\hline Do the radiation departments make sure that all HCWs wear TLD? & 55 & 28.2 & 140 & 71.8 \\
\hline $\begin{array}{l}\text { If one of the female of HCWs gets pregnant; will she be transferred } \\
\text { to another department? }\end{array}$ & 194 & 99.5 & 1 & 0.5 \\
\hline $\begin{array}{l}\text { Do you have an idea about different radiation risks which you are } \\
\text { exposed to at the workplace? Example }\end{array}$ & & & & \\
\hline -Acute radiation sickness such as nausea and vomiting & 85 & 43.6 & 110 & 56.4 \\
\hline $\begin{array}{l}\text {-Skin injuries: erythema, skin pigmentation, hair loss and desquamation } \\
\text {-Bone marrow depression }\end{array}$ & 102 & 52.3 & 93 & 47.7 \\
\hline -Cataract of the eye lens & 123 & 63.1 & 72 & 36.1 \\
\hline -Infertility in men and women & 78 & 40.0 & 121 & 60.0 \\
\hline -Cancers such as leukemia & 183 & 93.9 & 12 & 6.1 \\
\hline & 112 & 57.4 & 83 & 42.6 \\
\hline $\begin{array}{l}\text { Do you have an idea about different personal protective tools which } \\
\text { help to reduce radiation exposure? Example }\end{array}$ & & & & \\
\hline - Lead apron & 160 & 82.1 & 35 & 17.9 \\
\hline - Lead gloves & 98 & 50.3 & 97 & 49.7 \\
\hline - Eye goggles & 69 & 35.4 & 126 & 64.6 \\
\hline - Gonad shields & 72 & 36.9 & 123 & 63.1 \\
\hline - Thyroid shield & 55 & 28.2 & 140 & 71.8 \\
\hline
\end{tabular}

T1/2= Physical half life

$\mathrm{RSO}=$ Radiation Safety Officer
TLD=Thermo-Luminescent Detector

ALARA: As Low As Reasonably Achievable. 
Table 2 showed the number of HCWs who were highly aware of radiation protection procedures regarding the transference of female health care workers to another department when they get pregnant $(99.5 \%)$ followed by awareness of infertility in men and women HCWs as a risk of occupational radiation exposure and familiarity with the terms RSO ( Radiation Safety Officer) (93.9\% and $89.7 \%$, respectively) followed by knowing what TLD badge or pocket dosimeter are $(84.1 \%)$, familiarity with terms of distance and shielding $(82.1 \%$ and $83.6 \%)$ and lead apron as a protective tool reducing radiation exposure $(82.1 \%)$. However, the number of health care workers who responded that radiation departments make sure that all HCWs should wear TLD is low (28.2\%). Familiarity with the 10 days rule concept $(33.3 \%)$, of the fact that cataract of the eye lens is a risk of occupational radiation exposure (40.0\%) and of goggles, gonad shields and thyroid shields as protective tools against radiation exposure $(35.4 \%, 36.9 \%$ and $28.2 \%$, respectively).

Table 3: Safety practices of workers occupationally-exposed to ionizing radiation $(\mathrm{No}=195)$

\begin{tabular}{|l|c|c|c|c|}
\hline \multirow{2}{*}{ Safe practices of HCWs } & \multicolumn{2}{|c|}{ Yes (1) } & \multicolumn{2}{c|}{ NO (0) } \\
\cline { 2 - 5 } & No & $\mathbf{\%}$ & No & \% \\
\hline Do you wear lead apron? & 27 & 13.9 & 168 & 86.1 \\
\hline Do you wear lead gloves? & 22 & 11.3 & 173 & 88.7 \\
\hline Do you wear thyroid shield? & 0 & 0.0 & 195 & 100.0 \\
\hline Do you wear eye goggles? & 0 & 0.0 & 195 & 100.0 \\
\hline Do you use minimal procedure time? & 123 & 63.1 & 72 & 36.9 \\
\hline Do you keep enough distance from radiation source? & 145 & 74.4 & 50 & 25.6 \\
\hline Do you always wear personal dosimeter during work? & 67 & 34.4 & 128 & 65.6 \\
\hline
\end{tabular}

Table 3 showed that there is a large number of HCWs using safe practices to keep enough distance from radiation source and using minimal procedure time $(74.4 \%$ and $63.1 \%$, respectively) but a small number of workers practice wearing lead gloves and lead apron (11.3\% and $13.9 \%$, respectively) and no body wears thyroid shield or eye goggles. 
Table 4: Level of awareness and practices of radiation protection procedures among exposed workers in the three radiation units included in the study $(\mathbf{N o}=195)$.

\begin{tabular}{|c|c|c|c|c|c|c|c|}
\hline Items & $\begin{array}{r}\text { Radio } \\
\text { Dep }\end{array}$ & $\begin{array}{l}\text { gnosis } \\
\text { nent }\end{array}$ & $\begin{array}{r}\text { Radi } \\
\text { Dep }\end{array}$ & $\begin{array}{l}\text { erapy } \\
\text { ment } \\
\end{array}$ & $\begin{array}{l}\mathrm{Nu} \\
\text { me } \\
\text { Un }\end{array}$ & $\begin{array}{l}\text { ear } \\
\text { ine } \\
22)\end{array}$ & p-value \\
\hline Awareness & No & $\%$ & No & $\%$ & No & $\%$ & \multirow{4}{*}{0.15} \\
\hline Awareness Grade & \multicolumn{6}{|c|}{ [Mean awareness score $16.05 \pm 3.5$ (out of 23 )] } & \\
\hline $\begin{array}{l}\text { Unsatisfactory } \\
(95) \\
(48.7 \%) \\
\end{array}$ & 55 & 45.8 & 25 & 47.2 & 15 & 68.2 & \\
\hline $\begin{array}{l}\text { Satisfactory } \\
(100) \\
\quad(51.3 \%)\end{array}$ & 65 & 54.2 & 28 & 52.8 & 7 & 31.8 & \\
\hline Practice & No & $\%$ & No & $\%$ & No & $\%$ & \\
\hline Practice grade & & pra & ce sc & $3.3 \pm$. & 000 & & $\chi^{2}=0.5$ \\
\hline $\begin{array}{l}\text { In-adequate } \\
(160)(82.0 \%)\end{array}$ & 100 & 83.3 & 43 & 81.1 & 17 & 77.3 & 0.8 \\
\hline $\begin{array}{l}\text { Adequate (35) } \\
(18.0) \%\end{array}$ & 20 & 16.7 & 10 & 18.9 & 5 & 22.7 & \\
\hline
\end{tabular}

Table (4) revealed that total satisfactory awareness score among HCWs is (51.3 $\%$ ) with no significant difference between different radiation units $(54.2 \%$ in radiodiagnosis, $52.8 \%$ in radiotherapy and $31.8 \%$ in nuclear medicine departments) and the mean awareness score is $16.05 \pm 3.5$ (out of 23 ). Only $18.0 \%$ of HCWs had adequate practice regarding radiation protection procedures with no significant difference between different radiation units and the mean practice score was $3.3 \pm .3$ out of 7 . 
Table (5): Association between radiation awareness and practices of exposed workers and demographic variables $\left(\mathrm{No}_{\mathrm{o}}=195\right)$

\begin{tabular}{|c|c|c|c|c|c|c|c|c|}
\hline \multirow{3}{*}{\begin{tabular}{|c|}
$\begin{array}{c}\text { Demographic } \\
\text { variables }\end{array}$ \\
Age (years):
\end{tabular}} & \multicolumn{4}{|c|}{ Awareness } & \multicolumn{4}{|c|}{ Practice } \\
\hline & \multicolumn{2}{|c|}{$\begin{array}{c}\text { Satisfactory } \\
(95)\end{array}$} & \multicolumn{2}{|c|}{$\begin{array}{c}\text { Unsatisfactory } \\
\text { (100) }\end{array}$} & \multicolumn{2}{|c|}{$\begin{array}{c}\text { Adequate } \\
\text { (35) }\end{array}$} & \multicolumn{2}{|c|}{$\begin{array}{c}\text { In } \\
\text { adequate } \\
(160)\end{array}$} \\
\hline & No & $\%$ & No & $\%$ & No & $\%$ & No & $\%$ \\
\hline $\begin{array}{ll}20-30 & (95) \\
31-40 & (60) \\
>40 & (40)\end{array}$ & $\begin{array}{l}50 \\
25 \\
20\end{array}$ & $\begin{array}{l}52.6 \\
26.3 \\
21.1\end{array}$ & $\begin{array}{l}45 \\
35 \\
20\end{array}$ & $\begin{array}{l}45.0 \\
35.0 \\
20.0\end{array}$ & $\begin{array}{c}18 \\
10 \\
7\end{array}$ & $\begin{array}{l}51.4 \\
28.6 \\
20.0\end{array}$ & $\begin{array}{l}77 \\
50 \\
33\end{array}$ & $\begin{array}{l}48.1 \\
31.3 \\
20.6\end{array}$ \\
\hline p- value: & \multicolumn{4}{|c|}{$\chi^{2}=1.8 \quad 0.4$} & \multicolumn{4}{|c|}{$\chi^{2}=.14 \quad 0.9$} \\
\hline \multicolumn{9}{|l|}{ Educational level: } \\
\hline $\begin{array}{l}\text { - Diploma (35) } \\
\text { - Bachelor (115) } \\
\text { - Higher educational } \\
\text { degree (45) }\end{array}$ & $\begin{array}{l}15 \\
38 \\
42\end{array}$ & $\begin{array}{l}15.8 \\
40.0 \\
44.2\end{array}$ & $\begin{array}{c}20 \\
77 \\
3\end{array}$ & $\begin{array}{c}20.0 \\
77.0 \\
3.0\end{array}$ & $\begin{array}{c}3 \\
6 \\
26\end{array}$ & $\begin{array}{l}8.6 \\
17.1 \\
74.3\end{array}$ & $\begin{array}{c}32 \\
109 \\
19\end{array}$ & $\begin{array}{l}20.0 \\
68.1 \\
11.9\end{array}$ \\
\hline$\overline{\text { p- value: }}$ & \multicolumn{3}{|c|}{$\chi^{2}=47.6$} & $00 *$ & \multicolumn{2}{|c|}{$\chi^{2}=63.2$} & \multicolumn{2}{|c|}{$0.0000^{*}$} \\
\hline \multicolumn{9}{|l|}{ Years of experience: } \\
\hline $\begin{array}{l}\leq 5 \text { years }(90) \\
5-10 \text { years }(63) \\
\geq 10 \text { years }(42)\end{array}$ & $\begin{array}{l}30 \\
30 \\
35\end{array}$ & $\begin{array}{l}31.6 \\
31.6 \\
36.8\end{array}$ & $\begin{array}{c}60 \\
33 \\
7\end{array}$ & $\begin{array}{c}60.0 \\
33.0 \\
7.0\end{array}$ & $\begin{array}{c}5 \\
6 \\
24\end{array}$ & $\begin{array}{l}14.3 \\
17.1 \\
68.6\end{array}$ & $\begin{array}{l}85 \\
57 \\
18\end{array}$ & $\begin{array}{c}53.1 \\
35.6 \\
11.25\end{array}$ \\
\hline p- value: & \multicolumn{3}{|c|}{$\chi 28.7=2$} & $00 *$ & \multicolumn{2}{|c|}{$x^{2}=56.2$} & \multicolumn{2}{|c|}{$0.0000 *$} \\
\hline \multicolumn{9}{|l|}{ Occupation: } \\
\hline $\begin{array}{l}\text { - Physician (105) } \\
\text { - Nurse (57) } \\
\text { - Physicists and } \\
\text { Technicians (33) }\end{array}$ & $\begin{array}{l}70 \\
15 \\
10\end{array}$ & $\begin{array}{l}73.7 \\
15.8 \\
10.5\end{array}$ & $\begin{array}{l}35 \\
42 \\
23\end{array}$ & $\begin{array}{l}35.0 \\
42.0 \\
23.0\end{array}$ & $\begin{array}{c}28 \\
4 \\
3\end{array}$ & $\begin{array}{c}80.0 \\
11.4 \\
8.6\end{array}$ & $\begin{array}{l}77 \\
53 \\
30\end{array}$ & $\begin{array}{l}48.1 \\
33.1 \\
18.8\end{array}$ \\
\hline p- Value: & \multicolumn{2}{|c|}{$\chi 2=29.5$} & & $00 *$ & \multicolumn{2}{|c|}{$\chi 2=11.8$} & \multicolumn{2}{|c|}{$.002 *$} \\
\hline
\end{tabular}




\begin{tabular}{|c|c|c|c|c|c|c|c|c|}
\hline \multicolumn{9}{|c|}{ Training courses for radiation safety: } \\
\hline -Yes (65) & 58 & 61.1 & 7 & 7.0 & 25 & 71.4 & 40 & 25.0 \\
\hline -NO (130) & 37 & 38.9 & 93 & 93.0 & 10 & 28.6 & 120 & 75.0 \\
\hline p- Value: & \multicolumn{4}{|c|}{$\chi 2=61.6 \quad 0.0000 *$} & \multicolumn{2}{|c|}{$\chi 2=25.8$} & \multicolumn{2}{|c|}{$0.0000 *$} \\
\hline
\end{tabular}

* Statistically significant

Table 5: showed that satisfactory awareness of radiation protection procedures among exposed workers was highly significantly associated with higher educational level (44.2\%), years of experience $\geq 10$ years $(36.8 \%)$, being a physician $(73.7 \%)$ and getting training courses $(61.1 \%)$ but age was not significantly associated with awareness. Also, adequate practice of radiation protection procedures among exposed workers was highly significantly associated with higher educational level (74.3\%), years of experience $\geq 10$ years $(68.6 \%)$, being a physician $(80.0 \%)$ and getting training courses $(71.4 \%)$ while age was not significantly associated with practice.

The present study also revealed non-significant correlation between awareness and practices of radiation protection procedures among HCWs in different departments; out of $95 \mathrm{HCWs}$ who had satisfactory awareness, only 35 had adequate practice; with a ratio of $36.8 \%$.

\section{Discussion}

To the best of the researcher's knowledge, this study is the first to investigate the awareness and practice of ionizing radiation protection procedures among health care workers who are occupationally exposed to radiation hazards in Zagazig University Hospitals.

The study group included physicians and non-physicians (i.e. nurses, physicists and technicians) who usually come in contact with patients during procedures involving ionizing radiation during their daily work duties.

In the present study, satisfactory awareness of ionizing radiation protection procedures among exposed workers was found in all departments (Radiology department, Clinical Oncology and Nuclear Medicine department and Nuclear Medicine Unit). Satisfactory awareness of HCWs 
concerning the personal radiation exposure measuring devices (TLD) and the safety precautions regarding time , distance and shielding was reported. Female HCWs in the three departments showed excellent awareness regarding precautions taken in case of pregnancy. The study also showed satisfactory awareness concerning-radiation exposure hazards mainly infertility and also awareness of the different radiation protective tools specially the apron (Table 2). This good awareness regarding these points may be because of the well-known radiation exposure hazards, the effect on the reproductive state, and the genetic mutations.

The low awareness, in the present study, concerning the 10 day rule (Table 2), may be owed to its not being exactly known by the name in spite of its application. In addition, pregnancy blood test is requested as a mandatory test before any procedure in Nuclear Medicine and Radiotherapy departments to exclude pregnancy.

Concerning the unsatisfactory awareness of cataract as a hazard (Table 2), may be because it is an uncommonly seen complication. In addition, eye goggles, like other protective shields as thyroid and gonads' shields, are not available in the investigated departments, hence the low awareness level. The shortage in the supply of personal dosimeters (TLD) and small number of HCWs using them, explains the low awareness level.

Satisfactory awareness of radiation protection procedures of exposed workers in this study was highly significantly affected by higher educational level, years of experience $\geq$ 10 years, being a physician and getting training courses (Table 5).

The present study was in accordance with Alzubaidi et al. (2017) ) in their study about assessment of knowledge and attitude of nurses towards ionizing radiation during radiography in Jeddah city; who stated that the level of knowledge was significantly associated with the level of educational degree and magnitude of practical experience among workers in radiology departments .

Alotaibi et al. (2015), consistent with this study, in their cross-sectional survey done to explore the awareness level of radiation risks among nurses working in Nuclear Medicine departments in Kuwait, showed that, almost all nurses were not aware of the ALARA (As Low As Reasonably Achievable )principle and they were not familiar with GeigerMueller counter. Most of these nurses 
were not able to read the dosimetry reports and they were not familiar with the terms RSO. This is found to agree with this study, which revealed a low percentage of nurses with satisfactory overall awareness level of radiation protection procedures, except for awareness of the term RSO. However, a large number of HCWs showed satisfactory awareness regarding keeping enough distance from radiation source and using minimal procedure time and hence they followed safe work practices regarding these two important safety measures(Table 2).

However, there were a small number of workers who wore lead gloves and lead aprons and no body wore thyroid shields and eye goggles (Table 3). This unsatisfactory result may be attributed to the fact that many items of radiation protection tools are not available like thyroid shields and eye goggles. Other tools had to be replaced by new ones like lead aprons and lead gloves. Lead aprons were not always worn due to their heavy weight and also enough numbers were not available.

In accordance with the present study, Bhatt (2013) reported poor practice in not wearing lead aprons and personal dosimeters due to poor availability in his hospitals in Nepal.
El-Feky et al. (2017) reported shortage in the personal monitoring devices in all radiology departments in Tanta University hospitals, Egypt, and found a small percentage of HCWs using them in NM departments in spite of the fact that they all received these devices. Similar to results of this study she reported inadequate practice concerning the use of some radiation protection tools like eye goggles and thyroid shields for the same reason (unavailability) in spite of their good awareness of their importance.

A study done in Sudan by Mohamed, 2015 on radiation safety awareness and practice in Sudanese medical facilities; he found that, despite the fact that all governmental and private hospitals were provided with lead aprons, radiographers were poorly using these safety tools which is consistent with the results of the present study regarding this point regarding the use of these devices.

Also, in a study in Taif, Saudi Arabia, the majority of participants used lead aprons. However about one fourth used lead gloves and gonad shields, and about one third only used thyroid shields. These results are consistent with the present study in the lack of practice; despite the fact that enough protective 
tools were available for them, (Ahmed, 2015).

Awosan et al. (2016) in a crosssectional study among radiology, radiotherapy and dentistry staff, found that there was good awareness of radiation hazards among the participants but, poor radiation protection practice was noted, which is similar to the present study.

An important factor that should be considered in this study is the rotation of nurses from radiological departments and their exchange with nurses from other non-radiological departments without enough training. This might have participated in the unsatisfactory overall results of this study.

However, adequate practice of radiation protection found among exposed workers was highly significantly associated with higher educational level, years of experience, being a physician and getting training courses (Table 5).

A study done on radiation-exposed health care workers in 16 hospitals in Tehran University of Medical Sciences, reported poor overall radiation protection awareness and radiation protection practice among participants (Alavi, 2017) and, unlike results of the present study, there was no relationship between practice and levels of education or service training. However, the same study found those years of experience was significantly related to practice of radiation protection which is similar to results of the present study.

Consistent with results of this study , Shabani et al. (2018) found, in their study in Iran, that radiation protection practice score in the group with years of experience $>15$ year was significantly higher than in the group with years of experience $\leq 15$ year. Also, Reagan and Slechta (2010) revealed that years of employment were significantly related to radiation protection practice.

Regarding the effect of occupation on practice of radiation protection ( Table 5), Abdellah et al. (2015) in their study on assessment of physicians' knowledge, attitude and practices of radiation safety at Suez Canal University Hospital found inadequate practice among physicians and they found only half of the physicians were using lead gloves which was contrary to our results.

\section{Conclusion and recommendations:}

This study revealed somewhat satisfactory awareness of safety measures among HCWs (physicians, nurses, physicists, and technicians). It 
alsorevealedinadequateimplementation of radiation safety measures in the workplace as well as insufficient protective practices by HCWs. These results mandate application of an assessment system to ensure better awareness level of HCWs, updated training courses, strict application of safety measures and ensure availability of all needed radiation protection tools.

\section{Conflict interest}

There is no conflict of interest.

\section{Funding}

None.

\section{Acknowledgment}

The authors would like to thank the physicians and other workers in Diagnostic Radiology (DR) department, Clinical Oncology and Nuclear Medicine (CO\&N) department, and Nuclear Medicine (NM) unit for support and generous cooperation.

\section{References}

1. Abdellah RA, Attia SA, Ahmed MF and Abdel-Halim WA (2015): Assessment of physicians' knowledge, attitude and practices of radiation safety at Suez Canal University Hospital, Egypt. Open J Radiol; $5: 250-5$.
2. Ahmed RM, Taha Elamin AM, Elsamani M and Hassan BW (2015): Knowledge and performance of radiographers towards radiation protection, Taif, Saudi Arabia. J Dent Med; 14:63-8.

3. Alavi SS, Dabbagh ST, Abbasi $M$ and Mehrdad R (2017): Medical radiation workers' knowledge, attitude, and practice to protect themselves against ionizing radiation in Tehran Province, Iran. J Educ Health Promot; 6: 58.

4. Alotaibi M, Bakir YY, Al-Abdulsalam A and Mohammed AM (2015): Radiation awareness among nurses in nuclear medicine departments. Australian Journal of Advanced Nursing; a quarterly publication of the Royal Australian Nursing Federation: 32 (3): 25-33.

5. Alzubaidi MA, Al Mutairi HH, Alakel SM, Al Abdullah HAS, Ibrahim Abdullah Albakri IA et al. (2017): Assessment of Knowledge and Attitude of Nurses towards Ionizing Radiation During Radiography in Jeddah City. The Egyptian Journal of Hospital Medicine; 69 (7): 2906-9.

6. Awosan KJ, Ibrahim MTO, Saidu SA, Ma'aji SM, Danfulani M et al. (2016): Knowledge of Radiation Hazards, Radiation Protection Practices and Clinical Profile of Health Workers in a Teaching Hospital in Northern Nigeria. J Clin Diagn Res; 10(8): LC07-LC12. doi: 10.7860/ JCDR/2016/20398.8394. 
7. Bhatt CR, Widmark A, Shrestha SL, Khanal T and Ween B (2013): Occupational radiation exposure in health care facilities. Kathmandu Univ Med J; 39:48-51

8. Bushong SC (2012): Radiologic science for technologists: Physics, Biology, and Protection (10th edition). Mosby: St. Louis.

9. El-Feky AA, El-Sallamy RM, El-Sherbeni AA and Hagras HE (2017): Safety measures among workers occupationally exposed to ionizing radiation in Tanta University Hospitals. Tanta Medical Journal; 45:16674.

10. IBM Corp. Released 2010. IBM SPSS Statistics for Windows, Version 19.0. Armonk, NY: IBM Corp.

11. International Atomic Energy Agency [IAEA] (2011): Radiation protection and safety of radiation sources: international basic safety standards interim edition. Vienna: IAEA; 2011.

12. Mohamed ATE (2015): Radiation safety awareness and practice in Sudanese medical facilities: a descriptive. Int J Sci Res; 4:2190-5.
13. Morishima $\mathrm{Y}$, Chida K, Shigeizumi K, Katahira Y, Seto H et al. (2012): [Importance of radiation education for nurses]. Nihon Hoshasen Gijutsu Gakkai zasshi; 68: 1373-8.

14. Reagan JT and Slechta AM (2010): Factors related to radiation safety practices in California. Radiol Technol; 81:538-47. [PubMed: 20606048]

15. Safi M, Aerab-Sheibani H, Namazi MH, Vakili H and Saadat H (2014): Academic training in radiation safety awareness and practice among Iranian residents/fellows. Heart Asia; 6:137-41.doi:10.1136.

16. Shabani F, Hasanzadeh H, Emadi A, Mirmohammadkhani M, Bitarafan-Rajabi A et al. (2018): Radiation Protection Knowledge, Attitude, and Practice (KAP) in Interventional Radiology. Oman Medical Journal; 33(2):141-7.

17. World Health Organization [WHO] (2016): Ionizing radiation, health effects and protective measures/ factsheet 29April 2016. https://www.who.int/news-room/ fact-sheets/detail/ionizing-radiationhealth-effects-and-protective-measures. 